\title{
Cellular signaling with nitric oxide and cyclic GMP
}

\section{F. Murad}

\section{Correspondence \\ F. Murad \\ Department of Integrative Biology, \\ Pharmacology and Physiology \\ Institute of M olecular Medicine \\ University of Texas \\ Houston Medical Center \\ Houston, TX 77030 \\ USA}

Presented at the Meeting

"NO Brazil, Basic and Clinical

Aspects of Nitric $O$ xide",

Foz do Iguaçu, PR, Brazil,

March 10-13, 1999.

Received May 28, 1999

Accepted July 8, 1999

\author{
Department of Integrative Biology, Pharmacology and Physiology, \\ Institute of M olecular Medicine, University of Texas, \\ Houston Medical Center, Houston, TX, U SA
}

\section{Abstract}

During the past two decades, nitric oxide signaling has been one of the most rapidly growing areas in biology. This simple free radical gas can regulate an ever growing list of biological processes. In most instances nitric oxide mediates its biological effects by activating guanylyl cyclase and increasing cyclic GMP synthesis. However, the identification of effects of nitric oxide that are independent of cyclic GMP is also growing at a rapid rate. The effects of nitric oxide can mediate important physiological regulatory events in cell regulation, cell-cell communication and signaling. Nitric oxide can function as an intracellular messenger, neurotransmitter and hormone. However, as with any messenger molecule, there can be too much or too little of the substance and pathological events ensue. Methods to regulate either nitric oxide formation, metabolism or function have been used therapeutically for more than a century as with nitroglycerin therapy. Current and future research should permit the development of an expanded therapeutic armamentarium for the physician to manage effectively a number of important disorders. These expectations have undoubtedly fueled the vast research interests in this simple molecule.

\section{Key words}

- Nitric oxide

- Nitric oxide synthase

- Guanylyl cyclase

- Cell signaling

\section{Introduction}

During the late 1960's and early 1970's cyclic GMP began to emerge as another potential second messenger. Several laboratories independently described the enzyme that catalyzed its formation from GTP, guanylyl cyclase, a new isoform of cyclic nucleotide phosphodiesterase that preferred to hydrolize and inactivate cyclic GMP and a novel cyclic GMP-dependent protein kinase, presumably its molecular target (Figure 1).

In our earliest studies with cyclic GMP we did numerous experiments where we added one agent or another to tissues or cells to correlate cyclic GMP accumulation with the function of the preparation. While these early studies were necessary and productive, we gained little insight into the regulation of cyclic GMP synthesis and its functions. We wanted to address two important questions: 1) how do hormones, neurotransmitters and various ligands regulate guanylyl cyclase activity and cyclic GMP synthesis? (i.e., what are the molecular coupling events), and 2) what are some biological functions of increased cyclic GMP levels? 


\section{Isoforms of guanylyl cyclase}

About 1973, Hiroshi Kimura and I began to examine guanylyl cyclase in cell-free systems. We learned that there was activity in both high speed supernatant and particulate fractions of most tissues. Furthermore, the activities were quite different (1-3). While both activities were inhibited by ATP, the soluble activity was more sensitive to ATP inhibition. Detergents increased the soluble activity 50 to $100 \%$ and the particulate activity 3- to 7-fold. Calcium ion could either activate or inhibit activity depending upon its concentration, but the soluble and particulate activates had different sensitivities to these effects. The most striking difference was that the soluble activity gave linear kinetics (double reciprocal plots) with regard to the substrate GTP, while the particulate activity gave curvilinear double reciprocal plots indicating cooperativity with respect to GTP. The Hill coefficient of the soluble enzyme was 1.0 while the particulate activity had a Hill coefficient of 1.7 (1-3).

From our subsequent work with the characterization and purification of the enzyme and the cloning of the cDNA's for guanylyl cyclase we were able to demonstrate that several isoforms and separate gene products were present in tissue (4-7). Similar studies have since been done by other laboratories, most notably in the laboratories of David Garbers and Gunter Schultz. Today we know that numerous soluble and particulate isoforms can exist (4-7).

Figure 1 - Enzymes involved in cyclic GMP synthesis, metabolism and function.

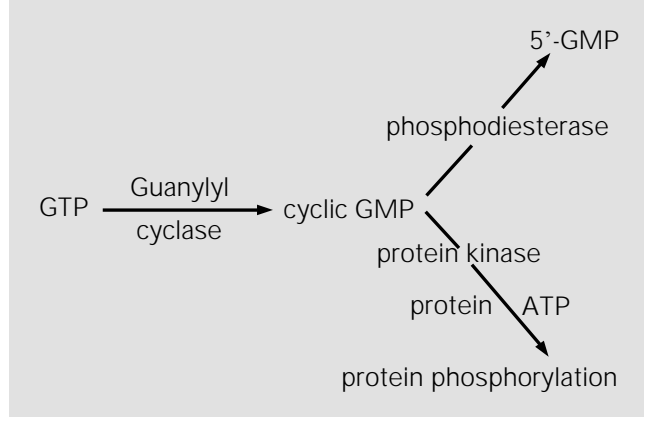

\section{Effects of azide, hydroxylamine and nitrite on cyclic GMP formation}

Our initial reaction to these data was that we were dealing with two different isoforms of guanylyl cyclase, one in the cytosolic compartment and one in the membranous compartment or organelles. However, we could not exclude that such effects were due to artefacts and experiments with crude high speed soluble and particulate preparations. Contaminating phosphatases, nucleotidases and cyclic nucleotide phosphodiesterases could also explain our observations. At the time we had no desire or plans to purify the protein(s). A simpler approach was to add azide, pyrophosphate, hydroxylamine, other phosphodiesterase inhibitors, fluoride, etc. individually or in combination and recharacterize the crude soluble and particulate guanylyl cyclase. Quite surprisingly, we found that azide, hydroxylamine and nitrite activated most but not all preparations (811). This was an exciting observation for us, because many hormones or ligands that increased cyclic GMP accumulation in intact cells failed to increase cyclic GMP synthesis in cell-free preparations. We, therefore, thought that hormone-receptor coupling to guanylyl cyclase activation would be a complicated molecular event that was disrupted in cell-free preparations. This was indeed the case as summarized below. We thought that the ability of azide, hydroxylamine and nitrite to increase cyclic GMP synthesis in intact and cell-free preparations could be used to understand hormonal regulation of guanylyl cyclase.

\section{Discovery of proteins required for azide activation and inhibition}

The activation by azide had a brief time lag before the time course became linear (811). Furthermore, the activation required air or oxygen and could be enhanced by the addition of thiols (8-11). This suggested that 
azide might be converted to another compound that served as the activating species. We then did a simple and obvious experiment where we mixed cell extracts that were activated by azide with extracts that were not activated.

We mixed crude supernatant fractions of rat liver that could be activated with azide with fractions of rat brain and rat heart, tissues without azide effects on guanylyl cyclase (Table 1; 8-11). Mixing extracts of liver with cerebral cortex resulted in an increased azide effect, while mixing liver extracts with heart extracts resulted in a loss of the azide effect. Our interpretation of these data was that azide activation required the presence of another factor present in liver extracts that when added to cerebral cortex permitted azide to activate the enzyme from both tissue extracts. Furthermore, heart extracts possessed one or more factors that blocked azide activation in the heart extracts and in liver extracts in the mixing experiments. Subsequent experiments proved these hypotheses to be true. The apparent activating factor(s) in liver and the inhibitor(s) in heart were nondialyzable and heat labile.

We decided to purify and characterize these activators and inhibitors (8-15). We thought that if we understood the mechanism of azide activation of guanylyl cyclase, perhaps we could reconstitute the appropriate materials to observe hormonal activation of guanylyl cyclase in cell-free preparations. This turned out to be the optimal approach and led us to the discovery of the first biological effects of nitric oxide.

We purified rat liver extracts and found that the macromolecular factor required for azide activation was catalase (8-15). Other heme-containing proteins such as horseradish peroxidase, however, could substitute for the catalase requirement (8-15). The factors in heart extracts were also purified and were hemoglobin and myoglobin (8-15). It became apparent that heme-containing proteins either permitted azide to activate guanylyl cyclase or blocked its activation.

\section{Effects of azide and nitrovasodilators on guanylyl cyclase activation, cyclic GMP accumulation in intact cells, and smooth muscle relaxation}

Azide, hydroxylamine and nitrite not only activated guanylyl cyclase in cell-free extracts but also increased cyclic GMP accumulation in numerous tissues and cell types (8-15). We also developed a rather homogenous bovine tracheal smooth muscle preparation where we could monitor motility in an organ bath with the addition of various agents and after quick freezing tissue segments we could measure cyclic nucleotide levels (1619). It was obvious that we should also add these new guanylyl cyclase activators to bovine tracheal smooth muscle segments and measure motility and cyclic GMP accumulation. We found that these agents increased cyclic GMP levels as expected and simultaneously caused relaxation in precontracted muscles (16-19). Similar results were observed when we examined gastrointestinal smooth muscle segments (16-19). We intentionally avoided vascular segments due to the heterogeneity of the preparations with endothelial cells, blood cells, fibroblasts, etc. We felt that we could not determine the cell types in which the cyclic GMP accumulation would occur due to the marked cellular het-

Table 1 - Effects of $\mathrm{NaN}_{3}$ on soluble guanylyl cyclase from rat liver, heart and cerebral cortex.

From Ref. 15, with permission.

\begin{tabular}{|c|c|c|c|}
\hline \multirow[t]{2}{*}{ Enzyme } & \multicolumn{2}{|c|}{ Cyclic GMP } & \multirow{2}{*}{$\frac{\text { Ratio }}{+\mathrm{N}_{3} /-\mathrm{N}_{3}}$} \\
\hline & $\begin{array}{l}-\mathrm{NaN}_{3} \\
\left(\mathrm{pmol} \mathrm{min}^{-1} \mathrm{mg}\right.\end{array}$ & $\begin{array}{r}+\mathrm{NaN}_{3} \\
\operatorname{rotein}^{-1} \text { ) }\end{array}$ & \\
\hline Liver & 38.8 & 595.4 & 15.3 \\
\hline Heart & 23.0 & 23.2 & 1.0 \\
\hline Cerebral cortex & 46.0 & 42.0 & 0.9 \\
\hline Liver + heart & 27.3 & 23.1 & 0.8 \\
\hline Liver + cerebral cortex & 23.0 & 899.0 & 39.1 \\
\hline
\end{tabular}


erogeneity. Thus, a correlation of cyclic GMP accumulation and muscle motility would be difficult.

After finding that these agents relaxed smooth muscle and that the increase in cyclic GMP was coincident with or preceded relaxation, we began to examine other smooth muscle relaxants such as nitroglycerin, nitroprusside, hydrazines, etc. (see Figure 2; 13-19). All of these agents increased cyclic GMP levels in smooth muscle, as well as other tissues, caused smooth muscle relaxation and activated guanylyl cyclase in most cell-free tissue extracts. We began to call these new guanylyl cyclase activators "nitrovasodilators". While these new nitrovasodilators did not require catalase to activate guanylyl cyclase preparations, their effects were inhibited by hemoglobin and myoglobin.

\section{Discovery of the biological effects of nitric oxide}

The effects of the growing list of "nitrovasodilators" with nitro or nitroso functionalities and the effects of heme-containing macromolecules as factors for either activation or inhibition of these agents suggested

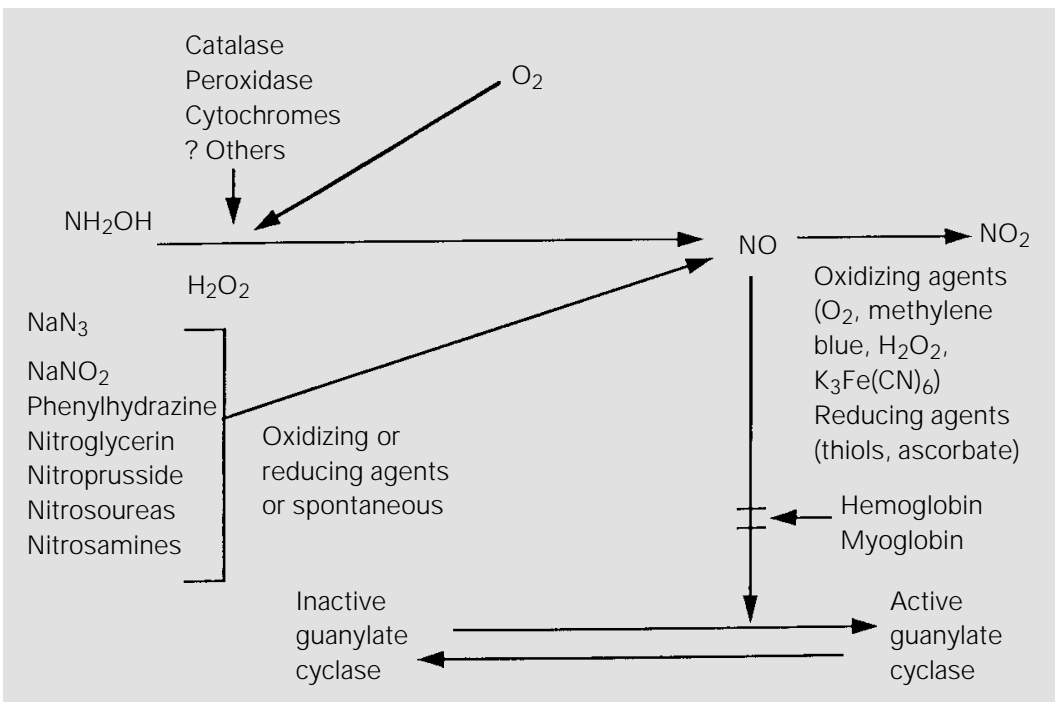

Figure 2 - Effects of nitrovasodilators on cyclic GMP synthesis. From Refs. 13 and 15, with permission. to us that perhaps the active intermediate or proximal activator of guanylyl cyclase could be nitric oxide. This was indeed the case (1420). Our first chemical generator to produce nitric oxide and ventilate the gas into guanylyl cyclase incubations was a success (16-20). Nitric oxide, unlike some other activators and nitrovasodilators, increased the activity of most guanylyl cyclase preparations and increased cyclic GMP levels in virtually all tissues tested with few exceptions. Since this was the first and only example of a freeradical activating an enzyme, we committed ourselves to purifying the isoforms of guanylyl cyclase to homogeneity to reexamine the effects of nitric oxide. We could not exclude the possibility that nitric oxide was being converted to yet some other activating species or that it was not inhibiting an inhibitor of the enzyme in our crude preparations.

After purifying the soluble guanylyl cyclase to homogeneity, nitric oxide activation was still observed (15,21). In fact, the apparent $\mathrm{K}_{\text {act }}$ (activation constant) for nitric oxide continued to decrease as we purified the enzyme and removed materials that trapped or complexed nitric oxide. Purified soluble guanylyl cyclase has a $\mathrm{K}_{\text {act }}$ or EC50 for nitric oxide in the order of 1 to $10 \mathrm{nM}$ depending upon the conditions of the assay and the presence of other materials such as thiols, proteins, sugars, etc. (22). These latter agents can act as traps or scavengers to form nitro or nitroso adducts and complexes to increase the $\mathrm{K}_{\text {act }}$ or EC50. In some cases these complexes can themselves be nitrovasodilators or nitric oxide "prodrugs" to rerelease nitric oxide under favorable conditions.

\section{Is nitric oxide a natural endogenous guanylyl cyclase activator?}

We proposed in 1978 that nitric oxide formation from some endogenous precursor could perhaps explain hormone, autacoid and neurotransmitter effects on cyclic GMP synthesis in intact cells and tissue $(13,15)$. 
Perhaps appropriate hormone treatment could influence the redox state of cells and/or the formation and metabolism of nitric oxide. We thought that some major technical advance would be required in order to test this hypothesis. If, indeed, nitric oxide was an endogenous regulator of the enzyme, one would expect that tissue levels of nitric oxide would be about 1 to $10 \mathrm{nM}$ (levels near the $\mathrm{K}_{\text {act }}$ or EC50) in order to be physiologically relevant and permit the fluctuations in nitric oxide concentrations to control enzyme activity. If the concentrations in tissue were much higher, one would expect the enzyme to always be activated and the physiological significance of nitric oxide would be less convincing and meaningful. Unfortunately, the assays for nitric oxide and its oxidation products (nitrite and nitrate) were crude colorimetric and spectrophotometric assays that were several orders of magnitude less sensitive than needed (about millimolar to micromolar). Thus, our hypothesis remained untestable for several years.

\section{Discovery of EDRF}

In 1980 Furchgott (21) presented a seminar in our department while I was at the University of Virginia. He was excited about his discovery of endothelial-derived relaxing factor (EDRF) and the ability of endothelial cells to generate and release a labile substance that produced relaxation of the underlying smooth muscle in vascular segments. The effects of EDRF shared many of the features and properties of nitrovasodilators and I suggested to him that perhaps increased cyclic GMP levels could explain his observation with light-induced and endothelium-induced relaxation. We even planned a collaboration to test this hypothesis which never materialized because of our subsequent move to Stanford University in 1981.

We then proceeded ourselves to demonstrate that EDRF formation did, indeed, increase cyclic GMP synthesis in the smooth muscle compartment of rat aorta segments with a variety of endothelium-dependent vasodilators such as acetylcholine, thrombin, ATP, bradykinin, etc. (23-29). We continued the work to also show that EDRF formation increased cyclic GMP-dependent protein kinase activity and altered protein phosphorylation of many endogenous smooth muscle proteins including the dephosphorylation of myosin light chain (23-29).

Cyclic GMP accumulation with nitrovasodilators or endothelium-dependent vasodilators produced similar effects on cyclic GMP accumulation, cyclic GMP-dependent protein kinase activation and altered ${ }^{32} \mathrm{PO}_{4}$ incorporation in the same family of proteins (23-29). Subsequently, we and others found that cyclic GMP decreased phosphoinositide metabolism and the formation of inositol phosphates including inositol trisphosphate by decreasing phospholipase $\mathrm{C}$ activity (30). These and other effects of cyclic GMP would be expected to decrease cytosolic free calcium and the activity of myosin light chain kinase, a calcium/calmodulindependent enzyme. The effect of cyclic GMPelevating agents to decrease cytosolic free calcium levels has been subsequently shown by many laboratories.

Because of the similarities of the effects of nitrovasodilators and EDRF-producing agents, we came to view EDRF as the "endogenous nitrate or endogenous nitrovasodilator" (28). Subsequently we and a number of laboratories showed that the effects of EDRF could be blocked with methylene blue, hemoglobin and other inhibitors of nitrovasodilator activation of guanylyl cyclase (see Figure 3). The effects of nitric oxide or EDRF can also be mimicked by atriopeptins which selectively activate particulate guanylyl cyclase $(28,31,32)$. In fact, we showed that one of the atriopeptin receptors (ANF-R1) is the extracellular domain of the transmembrane particulate guanylyl cyclase (33). This work has been confirmed by the cDNA cloning studies from Garbers' laboratory (34). 


\section{Effects of L-arginine on guanylyl cyclase activation and nitrite and nitrate formation}

In 1982 Degucci's laboratory reported that brain and/or neuroblastoma extracts possessed an endogenous substance that activated crude or partially purified preparations of soluble guanylyl cyclase (35). Furthermore, this substance was identified as Larginine. Activation by $\mathrm{L}$-arginine was blocked by hemoglobin and methylhydroxylamine, which blocked the effects of nitrovasodilators. We confirmed their observations and also found that L-arginine failed to block highly purified guanylyl cyclase (Murad F, unpublished observations).

Shortly thereafter Hibbs' laboratory in 1987 found that the cytotoxic effects of macrophages on tumor cells correlated with the accumulation of nitrite and nitrate in the conditioned media (36). The cytotoxic effects and accumulation of nitrite and nitrate were increased with L-arginine and blocked with L-arginine analogues such as L-Nmethyl arginine.

These were important observations that rapidly made sense in our laboratory and many other laboratories (37-40).

\section{Characterization of nitric oxide synthase and its isoforms}

Many laboratories including our own began to characterize, purify and clone this novel synthetic pathway that converted Larginine to nitric oxide and citrulline. Initially the most active laboratories included Marleta and Stuehr, Palmer and Moncada, Bredt and Snyder, Stuehr and Nathan and our own laboratory (see 5-7 and references therein).

The first nitric oxide synthase (NOS) isoform to be purified was the neuronal or brain NOS or NOS-1, also called type I NOS or constitutive NOS. This was followed shortly thereafter by NOS-2 or inducible NOS, also type II NOS, and then NOS-3 or endothelial NOS, type III NOS. Monoclonal and polyclonal antibodies to the purified isoforms and synthetic peptide fragments were produced as were the cDNA clones for these three gene products (see 5-7 and references therein). The chromosomal location
Figure 3 - Effects of endothelium-dependent vasodilators, nitrovasodilators and atriopeptins on cyclic GMP synthesis and vascular smooth muscle relaxation. NO, Nitric oxide; EDRF, endothelium-derived relaxing factor; ANF-1,2, atrial natriuretic factor 1 and 2; PLC, phospholipase C; DG, diacylglycerol; PI, phosphoinositides; IP, inositol phosphates.

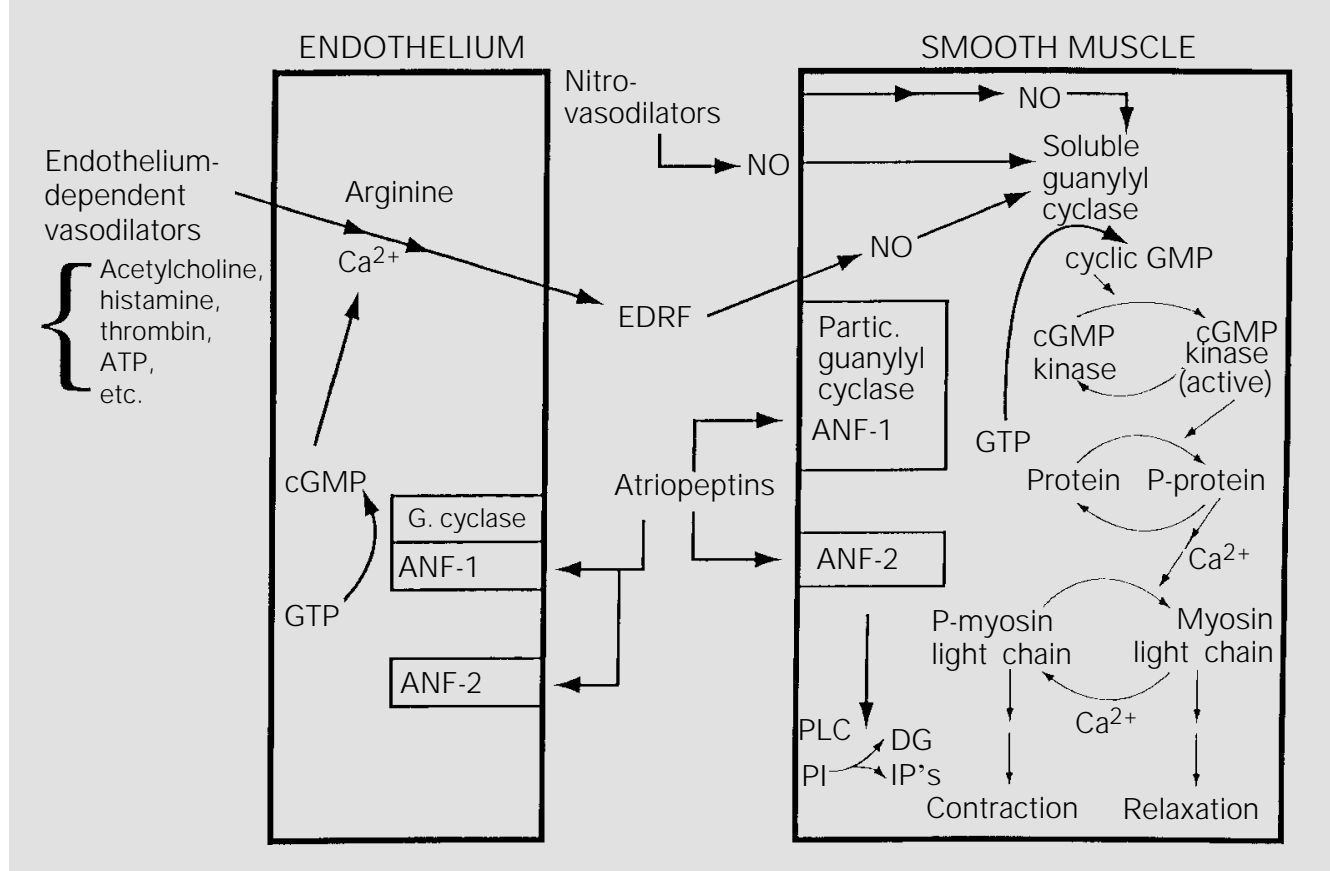


for each isoform has been identified as have the numerous cosubstrates, cofactors and prosthetic groups $\left(\mathrm{O}_{2}, \mathrm{NADPH}, \mathrm{FMN}, \mathrm{FAD}\right.$, tetrahydrobroptein, and heme) (see 7 and references therein). All three isoforms are regulated by calmodulin but only NOS- 1 and NOS-3 have apparent regulation with altered cytosolic free calcium concentrations. NOS-2 contains calmodulin as a bound component or subunit after translation and assembly such that dependency upon cytosolic free calcium levels is not demonstrable. The catalytically active isoforms exist as homodimers with tetrahydrobiopterin and heme serving to facilitate dimer formation. The carboxy terminal domain has considerable homology between the isoforms, and is homologous to cytochrome P450. The amino terminal domain has less homology. The homology of the three isoforms is only about 50 to $60 \%$ while the homology of a given isoform between species can be as great as 85 to $92 \%$.

NOS converts L-arginine to L-hydroxyarginine and subsequently to nitric oxide and citrulline as summarized in Figure 4. The transfer of electrons for the oxidation of the guanidino nitrogen of L-arginine and the precise role of each cofactor remain unresolved. This continues as an active area of investigation in many laboratories. Current X-ray crystallography studies with enzyme fragments should help elucidate the role of the cofactors and the enzyme mechanism.

Presumably the in situ activity of NOS can be regulated by the availability of substrate, cofactors and prosthetic groups. However, to date most of the regulation of NOS1 and NOS-3 has focused on the alterations of cytosolic free calcium caused by a myriad of hormones, autacoids, neurotransmitters, etc. (see Figure 5).

NOS-2 does not appear to be present under normal conditions in most cells. However, upon exposure to endotoxin (LPS), interferon $\gamma$, IL1, TNF $\alpha$ and other proinflammatory cytokines the levels of mRNA, protein and catalytic activity begin to increase within $1 \mathrm{~h}$ and reach maximal levels in 6 to $18 \mathrm{~h}$. Various antiinflammatory cytokines and glucocorticoids can decrease the induction of NOS-2. It is thought that some of the pharmacological and biological effects of these factors may be explained by

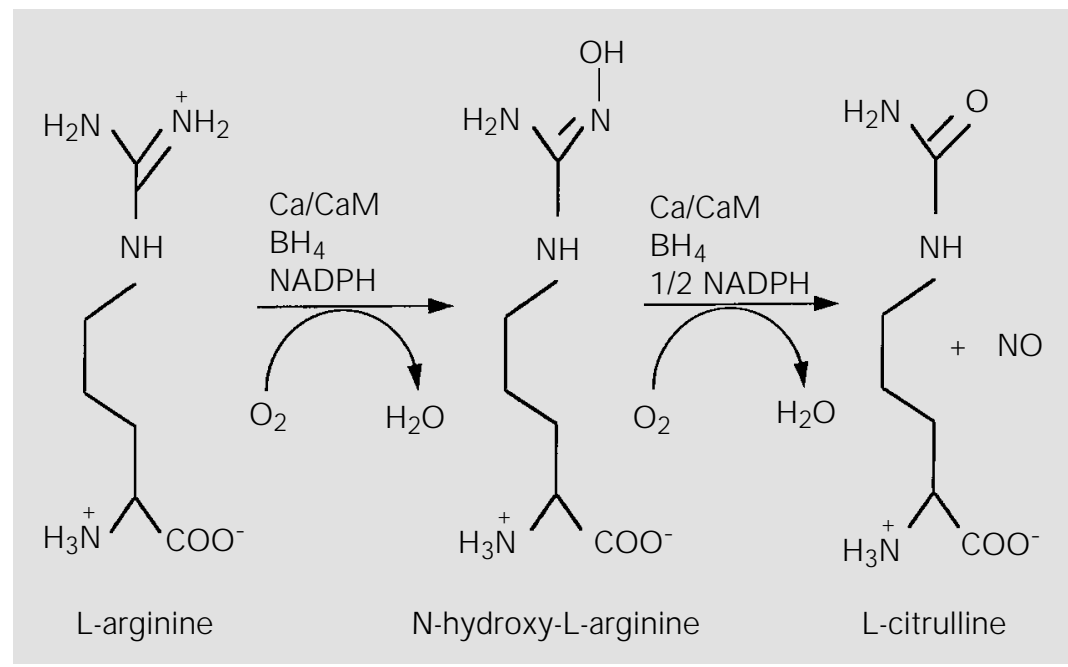

Figure 4 - The nitric oxide synthetic pathway. NADPH, Nicotinamide adenine dinucleotide phosphate.

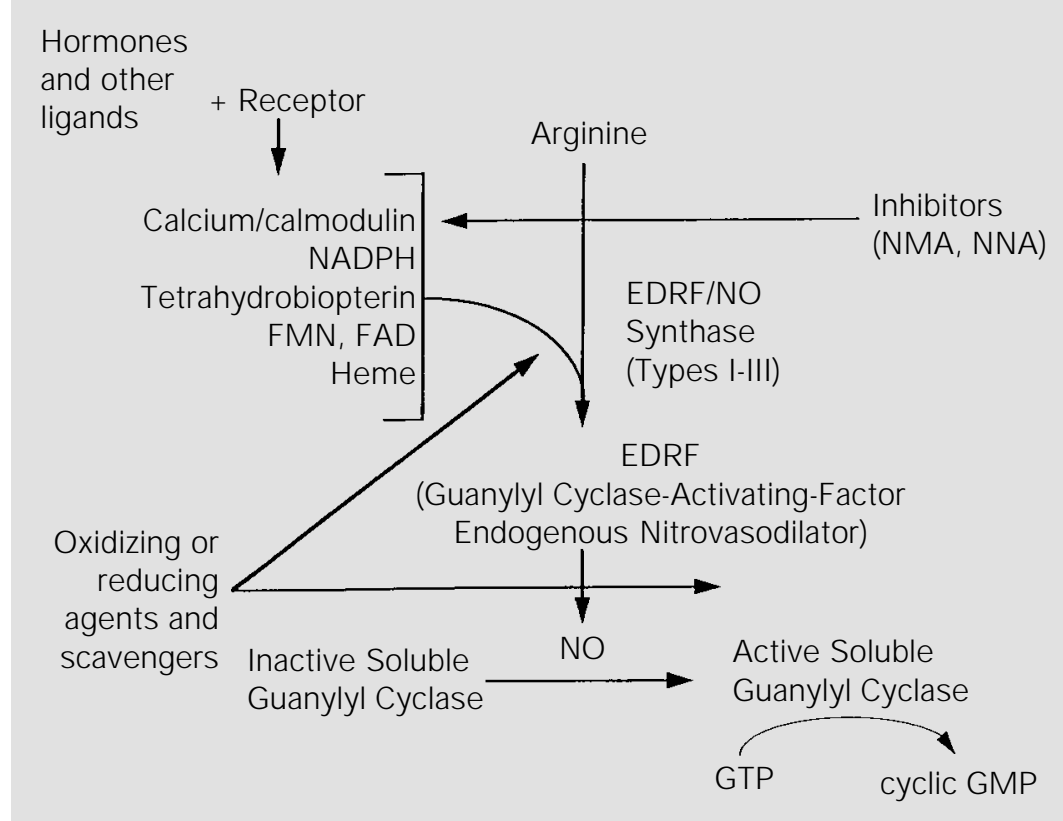

Figure 5 - Hormonal regulation of nitric oxide (NO) and cyclic GMP formation. NADPH, Nicotinamide adenine dinucleotide phosphate; FMN, flavin mononucleotide; FAD, flavin adenine dinucleotide; NMA, L-N-methyl arginine; NNA, L-N-nitro arginine. 
increased or decreased nitric oxide formation. For example, the hypotension observed in septic shock as well as the ensuing "multiple organ failure syndrome" may be due to excessive nitric oxide formation.

\section{Translational and post-translational modifications of NOS}

All of the isoforms can probably be phosphorylated by a variety of protein kinases including cyclic AMP-dependent protein kinase, cyclic GMP-dependent protein kinase, protein kinase $\mathrm{C}$ and $\mathrm{Ca}^{2+} /$ calmodulin-dependent protein kinase. With phosphorylation the activity of the enzyme can be increased or decreased. However, the physiological relevance of phosphorylation to regulate enzyme activity or enzyme translocation from one cellular compartment to another is unknown (5-7,37-41 and references therein). In some cell-free systems with purified NOS1 as many as 6 to $7 \mathrm{~mol}$ of phosphate can be incorporated into one monomer of protein (41).

NOS-3 is also myristoylated and palmitylated. The acylation probably participates in the location of this isoform in the plasma membrane and/or other organelles (42-45). Recently Michels' laboratory and Sessa's laboratory have described the association of NOS-3 with the caveolae of the plasma membrane (45). These structures also contain many other proteins participating in cell signaling events. Mechanisms to regulate and chaperon NOS-3 from the Golgi to the caveolae and the recycling of NOS-3 to the cytosol and perhaps back to the plasma membrane are areas of active investigation. These processes could perhaps serve as important sites for regulation and drug targeting.

The three gene products of NOS described to date, possible alternate mRNA splicing due to multiple promoters (i.e., NOS-1) (46) and various post-translational modifications should permit a multitude of NOS isoforms. Undoubtedly this will be a complex problem to resolve with regard to NOS functions, regulation and selective inhibition (see below). Some cells possess only one isoform while other cells have several isoforms with different subcellular locations and perhaps different functions.

\section{NOS inhibitors}

Numerous NOS inhibitors have been described. Novel arginine-based and guanidine-based antagonists are areas of active investigation in both academic and industrial laboratories (see 5-7 and references therein). Most inhibitors to date are competitive antagonists and may be partly selective for one or another isoform. Commercially available compounds may show as much as 100- to 200-fold selectivity for one or another isoform. Unfortunately, to date, there are no specific inhibitors of one or another isoform. Such agents could prove invaluable to sort out the NOS isoforms in various cell types and the biological events that they regulate. Furthermore, investigations in this area could result in highly selective and perhaps specific and efficacious therapeutic agents without numerous side effects since one or more isoforms of NOS are found in virtually all cells with few exceptions. Currently, some NOS inhibitors are in clinical trials for patients in septic shock.

\section{NO donors or prodrugs in clinical medicine}

A number of NO prodrugs have been used successfully since the use of nitroglycerin for angina pectoris more than a century ago. Other therapeutics of the "nitrovasodilator class" include nitroprusside, organic and inorganic nitrites and nitrates, nitrosamines, nitrogen mustards, hydrazines, nitrosoureas, etc. Many academic and industrial laboratories are actively synthesizing additional "NO-donors" that release NO at predictable rates in specific tissues or envi- 
ronments (see 7 and references therein).

A rapidly advancing area of clinical application is the inhalation of low concentrations of the NO gas (see 7 and references therein). Inhalation of low concentrations of NO has been beneficial in infants, children and adults with pulmonary hypertension, bronchospasm, and right to left cardiac shunts from congenital heart defects. Interestingly, nitric oxide at low concentrations is quite stable and minimally reactive. However, at higher concentrations NO can interact with many transition metals, heme-containing proteins, and thiol groups and can oxidize functionalities on polynucleotides (RNA and DNA) and proteins and can form strand breaks in polynucleotides (Figure 6).

\section{Conclusions}

Since our discovery of the first biological effects of nitric oxide more than two decades ago, more than 20,000 publications have appeared on this topic. However, numerous important questions remain to be addressed and answered. What excitement it has been for those of us who joined the field early and were able to see the major advances and progress in recent years!

In recent years a number of laboratories have made significant advances in nitric oxide research. Some areas of active research are listed in Table 2. Undoubtedly, other interesting areas will also emerge and require increasing research and attention.

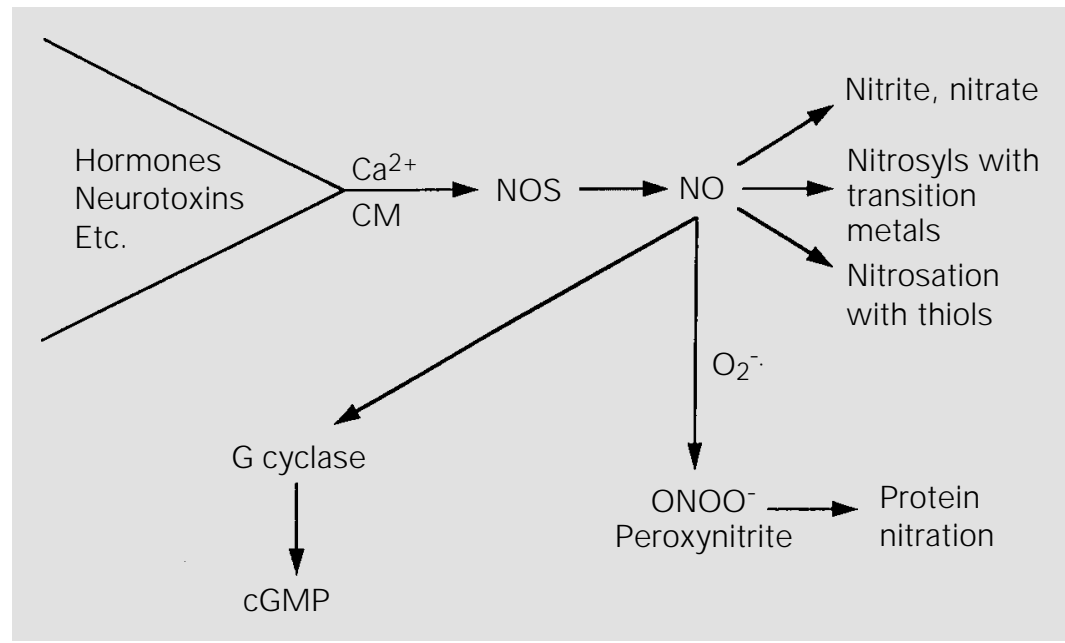

Figure 6 - Fate of nitric oxide (NO). NOS, NO synthase.

Table 2 - Areas of active NO research.

- Transcriptional regulation

- Overexpression and gene therapy

- Gene knockouts

- Histochemistry, hybridization

- Acylation, phosphorylation, etc.

- Cell types with NOS isoforms and functions

- Cyclic GMP-mediated effects

- Non-cyclic GMP-mediated effects

- Selective/specific NOS inhibitors

- Novel NO donors

\section{Acknowledgments}

I would like to thank the numerous trainees and collaborators who have shared in this work with me. I also wish to thank numerous agencies for their past grant support and Mrs. Marcia Waldbillig for typing this manuscript.

\section{References}

1. Kimura $H \&$ M urad F (1974). Evidence for two different forms of guanylate cyclase in rat heart. J ournal of Biological Chemistry, 249: 6910-6919.

2. Kimura $\mathrm{H} \&$ Murad F (1975). Two forms of guanylate cyclase in mammalian tissues and possible mechanisms for their regulation. Metabolism, 24: 439-445.

3. Kimura $H \&$ Murad F (1975). Increased particulate and decreased soluble guany- late cyclase activity in regenerating liver, fetal liver, and hepatoma. Proceedings of the National Academy of Sciences, USA, 72: 1965-1969.

4. Waldman SA \& Murad F (1987). Cyclic GMP synthesis and function. Pharmacological Reviews, 39: 163-196.

5. Murad F (Editor) (1994). Cyclic GMP synthesis, metabolism and function. In: Advances in Pharmacology. Vol. 26. Academ- ic Press, New York.

6. Murad $F$ (1994). The role of nitric oxide in modulating guanylyl cyclase. Neurotransmission, 10: 1-4.

7. Ignarro $L \& \&$ Murad F (Editors) (1995). Nitric oxide: biochemistry, molecular biology, and therapeutic implications. In: Advances in Pharmacology. Vol. 34. Academic Press, New York.

8. Kimura H, Mittal CK \& Murad F (1975). 
Activation of guanylate cyclase from rat liver and other tissues with sodium azide. J ournal of Biological Chemistry, 250: 8016-8022.

9. Mittal CK, Kimura H \& Murad F (1975). Requirement for a macromolecular factor for sodium azide activation of guanylate cyclase. J ournal of Cyclic Nucleotide Research, 1: 261-269.

10. Kimura H, Mittal CK \& Murad F (1975). Increases in cyclic GMP levels in brain and liver with sodium azide, an activator of guanylate cyclase. Nature, 257: 700702.

11. Kimura H, Mittal CK \& Murad F (1976). Appearance of magnesium guanylate $c y$ clase activity in rat liver with sodium azide activation. J ournal of Biological Chemistry, 251: 7769-7773.

12. Mittal CK, Kimura H \& Murad F (1977). Purification and properties of a protein required for sodium azide activation of guanylate cyclase. J ournal of Biological Chemistry, 252: 4348-4390.

13. Murad F, Mittal CK, Arnold WP, Katsuki S \& Kimura H (1978). Guanylate cyclase: Activation by azide, nitro compounds, nitric oxide, and hydroxyl radical and inhibition by hemoglobin and myoglobin. Advances in Cyclic Nucleotide Research, 9: 145-158.

14. Murad F, Mittal CK, Amold WP, Ichihara K, Braughler E \& El-Zayat M (1978). Properties and regulation of guanylate cyclase: Activation by azide, nitro compounds and hydroxyl radical and effects of heme containing proteins. Proceedings of the NATO Advanced Studies Institute on Cyclic Nucleotides, Italy, 1977. In: Folca G \& Paoletti R (Editors), Molecular Biology and Pharmacology of Cyclic Nucleotides. Elsevier, Amsterdam, 33-42.

15. Murad F, Mittal CK, Amold WP \& Braughler J M (1978). Effect of nitro-compound smooth muscle relaxants and other materials on cyclic GMP metabolism. Proceedings of the 7th International Congress of Pharmacology, Paris, France, J uly, 1978. In: Stocklet J C (Editor), Advances in Pharmacology and Therapeutics. Vol. 3. Ions, Cyclic Nucleotides, Cholinergy. Pergamon Press, New York, 123-132.

16. Katsuki S, Arnold W, Mittal CK \& Murad F (1977). Stimulation of guanylate cyclase by sodium nitroprusside, nitroglycerin and nitric oxide in various tissue preparations and comparison to the effects of sodium azide and hydroxylamine. J ournal of $\mathrm{Cy}$ clic Nucleotide Research, 3: 23-35.

17. Katsuki S, Arnold WP, Mittal CK \& Murad $F$ (1977). Stimulation of formation and ac- cumulation of cyclic GMP by smooth muscle relaxing agents. Proceedings of the 2nd J apanese Cyclic Nucleotide Conference, J uly 7-9, Osaka, J apan, 44-50.

18. Katsuki $S \&$ M urad F (1977). Regulation of cyclic 3',5'-adenosine monophosphate and cyclic 3',5'-guanosine monophosphate levels and contractility in bovine tracheal smooth muscle. Molecular Pharmacology, 13: 330-341.

19. Katsuki S, Arnold WP \& Murad F (1977). Effect of sodium nitroprusside, nitroglycerin and sodium azide on levels of cyclic nucleotides and mechanical activity of various tissues. J ournal of Cyclic Nucleotide Research, 3: 239-247.

20. Arnold WP, Mittal CK, Katsuki S \& Murad F (1977). Nitric oxide activates guanylate cyclase and increases guanosine $3^{\prime}, 5^{\prime}$ monophosphate levels in various tissue preparations. Proceedings of the National Academy of Sciences, USA, 74: 32033207.

21. Furchgott R \& Zarwodski J (1980). The obligatory role of endothelial cells in the relaxation of arterial smooth muscle to acetylcholine. Nature, 288: 373-376.

22. Braughler J M, Mittal CK \& Murad $F$ (1979). Purification of soluble guanylate cyclase from rat liver. Proceedings of the National Academy of Sciences, USA, 76: 219-222.

23. Rapoport RM \& Murad F (1983). Agonistinduced endothelial-dependent relaxation in rat thoracic aorta may be mediated through cyclic GMP. Circulation Research, 52: 352-357.

24. Rapoport RM \& M urad F (1983). Endothelium-dependent and nitrovasodilator-induced relaxation of vascular smooth muscle: Role for cyclic GMP. J ournal of Cyclic Nucleotide and Protein Phosphorylation Research, 9: 281-296.

25. Rapoport RM, Draznin MB \& Murad F (1983). Endothelium-dependent vasodilator- and nitrovasodilator-induced relaxation may be mediated through cyclic GMP formation and cyclic GMP-dependent protein phosphorylation. Transactions of the Association of American Physiology, 96: 19-30.

26. Rapoport RM, Draznin MB \& Murad F (1983). Endothelium dependent relaxation in rat aorta may be mediated through cyclic GMP-dependent protein phosphorylation. Nature, 306: 274-276.

27. Fiscus RR, Rapoport RM \& Murad F (1983). Endothelium-dependent and nitrovasodilator-induced activation of cyclic GMP-dependent protein kinase in rat aorta. J ournal of Cyclic Nucleotide and
Protein Phosphorylation Research, 9: 415425.

28. Rapoport RM \& Murad F (1984). Effect of cyanide on nitrovasodilator-induced relaxation, cyclic GMP accumulation and guanylate cyclase activation in rat aorta. European J ournal of Pharmacology, 104: 6170.

29. Rapoport RM, Draznin $M \&$ \& Murad $F$ (1982). Sodium nitroprusside-induced protein phosphorylation in intact rat aorta is mimicked by 8-bromo-cyclic GMP. Proceedings of the National Academy of Sciences, USA, 79: 6470-6474.

30. Hirata $\mathrm{M}$, Kohse $\mathrm{K}$, Chang $\mathrm{CH}$, Ikebe $\mathrm{T} \&$ Murad F (1990). Mechanism of cyclic GMP inhibition of inositol phosphate formation in rat aorta segments and cultured bovine aortic smooth muscle cells. J ournal of Biological Chemistry, 265: 12681273.

31. Winquist RM, Faison EP, Waldman SA Schwartz K, Murad F \& Rapoport RM (1984). Atrial natriuretic factor elicits an endothelium independent relaxation and activates particulate guanylate cyclase in vascular smooth muscle. Proceedings of the National Academy of Sciences, USA, 81: 7661-7664.

32. Waldman SA, Rapoport RM \& Murad F (1984). Atrial natriuretic factor selectively activates particulate guanylate cyclase and elevates cyclic GMP in rat tissues. J ournal of Biological Chemistry, 259: 14332-14334.

33. Kuno T, Andresen J W, Kamisaki $Y$, Waldman S, Chang LY, Saheki S, Leitman DC, Nakane M \& Murad F (1986). Copurification of an atrial natriuretic factor receptor and particulate guanylate cyclase from rat lung. J ournal of Biological Chemistry, 261: 5817-5823.

34. Garbers DL (1991). Guanyl cyclase linked receptors. Pharmacology and Therapeutics, 50: 337-345.

35. Degucci T \& Yoshiako M (1982). L-Arginine identified as an endogenous activator for soluble guanylate cyclase from neuroblastoma cells. J ournal of Biological Chemistry, 257: 10147-10152.

36. Hibbs J , Traintor R \& Vanin Z (1987). Macrophage cytotoxicity. Role for l-arginine deaminase and imino nitrogen activation to nitrate. Science, 235: 473-474.

37. Murad F (1988). The role of cyclic GMP in the mechanism of action of nitrovasodilators, endothelium-dependent agents and atrial natriuretic peptide. Biochemical Society Transactions, 16: 490-492.

38. Murad F, Leitman D, Waldman S, Chang $\mathrm{CH}$, Hirata M \& Kohse K (1988). Effects of 
nitrovasodilators, endothelium-dependent vasodilators and atrial peptides on CGMP. Proceedings of the Cold Spring Harbor Symposium on Quantitative Biology, Signal Transduction, 53: 1005-1009.

39. Murad F (1989). Modulation of the guanylate cyclase-cGMP system by vasodilators and the role of free radicals as second messengers. Proceedings of the NATO Advanced Studies Institute on Vascular Endothelium: Receptors and Transduction Mechanisms, Porto Carros, Greece, J une, 1988. In: Catravas J D, Gillis CN \& Ryan US (Editors), Vascular Endothelium. Plenum Publishing Co., New York, 157-164.

40. Murad $F$ (1989). Mechanisms for hormonal regulation of the different isoforms of guanylate cyclase. In: Gehring $Y$, Helmreich E \& Schultz G (Editors), Proceedings of the 40th Mosbach Collo- quium on Molecular Mechanisms of Hormone Action, April 1989. Springer, Heidelberg, 186-194.

41. Nakane M, Mitchell J A, Förstermann U \& Murad F (1991). Phosphorylation by calcium calmodulin-dependent protein kinase II and protein kinase $\mathrm{C}$ modulates the activity of nitric oxide synthase. Biochemical and Biophysical Research Communications, 180: 1396-1402.

42. Pollock J S, Förstermann U, Mitchell J A, Warner TD, Schmidt HHHW, Nakane M \& Murad F (1991). Purification and characterization of particulate EDRF synthase from cultured and native bovine aortic endothelial cells. Proceedings of the National Academy of Sciences, USA, 88: 10480-10484.

43. Pollock $J$, Klinghofer $V$, Förstermann $U$ \& Murad F (1992). Endothelial nitric oxide synthase is myristylated. FEBS Letters, 309: 402-404.

44. Robinson LJ , Busconi L \& Michel T (1995). Agonist-modulated palmitoylation of endothelial nitric oxide synthase. J ournal of Biological Chemistry, 270: 995-998.

45. Shaul PW, Smart EJ, Robinson LJ, German Z, Yuhanna IS, Ying Y, Anderson R \& Michel T (1996). Acylation targets endothelial nitric-oxide synthase to plasmalemmal caveolae. J ournal of Biological Chemistry, 271: 6518-6522.

46. Xie J , Roddy P, Rife T, Murad F \& Young A (1995). Two closely linked but separate promoters for human neuronal nitric oxide synthase gene transcription. Proceedings of the National Academy of Sciences, USA, 92: 1242-1246. 